\title{
Relações entre a Atividade Carbonífera e o Rural em Candiota, RS, Brasil: análises sobre representações sociais em um contexto de dilemas sobre a energia
}

\author{
Viviane Camejo Pereira ${ }^{1}$ e Jalcione Almeida²
}

Resumo: A geração de energia termelétrica à base de carvão mineral tem despertado distintas opiniões e significados. O objetivo deste artigo é investigar as representações sociais que grupos e atores sociais no espaço rural compartilham em torno da temática da exploração do carvão mineral no município de Candiota (RS), sul do Brasil. Foi possível identificar algumas representações que compõem a relação entre o rural e o carvão no município. Do ponto de vista teórico e metodológico, optou-se pela Teoria das Representações Sociais, de Serge Moscovici, e pela abordagem estrutural das representações sociais de Jean-Claude Abric. Foram entrevistadas 46 pessoas entre janeiro e março de 2012. A representação central da atividade carbonífera no caso estudado situa-se em torno da ideia de "crescimento econômico", retratando um discurso embasado no universo reificado de alguns setores socioeconômicos e a pressão à inferência sobre grupos. Os entrevistados, em sua maioria, são favoráveis à atividade (53\%), enquanto $28 \%$ são contrários e 19\% não se consideram nem favoráveis nem contrários, variando seus argumentos conforme a posição social. No caso estudado, o grau de dependência em relação à exploração do carvão é instável e dinâmico.

Palavras-chaves: Representações sociais, carvão mineral, rural, Candiota.

Abstract: The generation of thermoelectric coal to power has aroused different opinions and significances. The objective of this paper is to investigate the social representations that groups and social actors in rural areas share about the matter of exploitation of coal in the municipality of Candiota (RS), Southern Brazil. Some representations that compose the relationship between rural and coal in the county were identified. From a theoretical

1. Licenciada em Ciências Biológicas. Mestra em Desenvolvimento Rural e doutoranda no Programa de Pós-graduação em Desenvolvimento Rural na Universidade Federal do Rio Grande do Sul (RS), Brasil. E-mail: vivianecamejop@gmail.com

2. Professor Doutor no Programa de Pós-Graduação em Sociologia (PPGS) e Programa de PósGraduação em Desenvolvimento Rural (PGDR), ambos da Universidade Federal do Rio Grande do Sul (UFRGS). Coordenador do grupo de pesquisa Tecnologia, Meio Ambiente e Sociedade. E-mail: jal@ufrgs.br 
and methodological point of view, were based on the Theory of Social Representations of Serge Moscovici, and the structural approach of social representations of Jean-Claude Abric. We interviewed 46 people between January and March 2012. The central representation of the coal activity in the case study is located around the idea of "economic growth", depicting a discourse of the reified universe of some socio-economic sectors and the pressure to make inferences about groups. Most of the interviewed people are favorable to the activity (53\%), while $28 \%$ are opposed and $19 \%$ do not consider themselves neither favorable or contrary, varying their arguments according to social position. In the case studied, the level of dependence on coal exploration is unstable and dynamic.

Key-words: Social representations, coal, rural, Candiota.

Classificação JEL: O13.

DOI: http://dx.doi.org/10.1590/1234-56781806-9479005301007

\section{Introdução}

A construção da problemática de estudo está alicerçada na atualidade do debate sobre a questão energética brasileira e suas implicações no desenvolvimento rural local. As discussões internacionais acerca do desenvolvimento e da matriz energética mundial têm sido alvo de conferências internacionais. Destacam-se a Conferência de Estocolmo sobre o Ambiente Humano das Nações Unidas, em 1972, a Comissão Mundial sobre Meio Ambiente e Desenvolvimento, que resultou no Relatório Brundtland - Nosso Futuro Comum, em 1987, a II Conferência das Nações Unidas sobre Meio Ambiente e Desenvolvimento (Rio-92) e a Conferência das Nações Unidas sobre Desenvolvimento Sustentável (Rio +20 ). Tratando dos eventos mais recentes, na Rio-92, os Estados Unidos, que tinham a matriz energética baseada na energia termelétrica a carvão mineral, resistiram aos acordos internacionais que previam a redução de emissão de gases na atmosfera. Na Rio + 20, em 2012, discutiu-se a necessidade da diminuição do uso de combustíveis fósseis como o carvão mineral, porém não houve exigências quanto à assinatura de mais acordos por parte dos países, foi apenas reforçada a necessidade de observar o disposto na Rio-92 (RIO + 20, 2012). Atualmente, a geração de energia elétrica nos Estados Unidos continua tendo como base a energia termelétrica; porém, em 2012, observou-se sua equiparação ao uso de gás natural (EIA, 2012). No Brasil, o fomento à produção de energia elétrica a partir do carvão mineral não é recente e atualmente possui pouca representatividade como matriz energética. $\mathrm{O}$ município de Candiota (RS) ${ }^{3}$ tem a maior jazida de carvão explorada a céu aberto do Brasil, utilizada na geração de energia termelétrica, fonte de reserva energética no estado do Rio Grande do Sul em tempos de estiagem, quando baixam os níveis das barragens hidrelétricas. A matriz econômica do município, além da atividade carbonífera, é baseada nas atividades agropecuárias.

A problemática do carvão mineral surge no contexto em que as pessoas almejam a sua consolidação e maios investimentos públicos, já que as fases A e B da Usina Termelétrica já estavam obsoletas, carecendo de novas medidas de infraestrutura física para continuidade. Fomentada pelo PAC, do governo Dilma, é construída a fase C. Segundo relatos, muitos empregos foram gerados durante a construção, mas, de forma parecida a outros empreendimentos energéticos no Brasil, ao final, muitas pessoas foram dispensadas, passando a integrar o contingente de trabalhadores desempregados do município.

3. A criação do município de Candiota se deve ao desmembramento de Bagé, em 2001, que deu origem também aos municípios de Hulha Negra e Aceguá. Atualmente, o município é constituído por cinco distritos: Candiota, Baú, Passo Real de Candiota, Jaguarão Grande e Seival. 
Observando-se a evolução do número de funcionários da CGTEE/Eletrobrás - Usina Termelétrica, que, ao atingir 96,3\% da construção da fase C da usina (Candiota III, $350 \mathrm{MW}$ ), contou com mais de 4.130 trabalhadores em 31 de agosto de 2010. Mais tarde, em 31 de outubro de 2010, eram 3.080 trabalhadores, já incluídos os 450 chineses que participaram da transferência de tecnologia. Em 31 de dezembro de 2010, eram 950 operários envolvidos com a construção da fase C, sendo 180 chineses. No final de março de 2013, segundo divulgação de dados gerados pela empresa CGTEE/Eletrobrás, eram 526 funcionários.

Apesar da realidade dos impactos sociais de uma inflação e, em seguida, uma drástica redução de empregos nas construções de termelétricas e em outras grandes obras, em março de 2013 foi aprovada pelo governo federal, como mencionado acima, a inclusão do carvão mineral nos leilões de energia. Ao mesmo tempo, o Conselho Estadual de Meio Ambiente do Rio Grande do Sul e entidades representativas de empresas discutem a flexibilização da lei que delimita as quantidades de emissões de poluentes pelas usinas termelétricas. Neste contexto, a familiarização da atividade carbonífera, que integra a noção de crescimento econômico, vai de encontro aos antigos pressupostos, como de não poluição e os de contra fomento da atividade. Aproximadamente $60 \%$ dos entrevistados não demonstraram real preocupação com as questões ambientais, pois estavam ancorados na certeza de que a atividade estava fadada à estagnação ou, para alguns, até mesmo a desaparecer. É como se a maioria dos entrevistados não quisesse se preocupar com algo tendente a desaparecer, a estagnar ou diminuir, a fim de evitar um desgaste.

Sendo assim, as indagações que regem a problemática deste artigo são: em meio ao contexto de debate local sobre desenvolvimento econômico, de que forma é entendida a atividade carbonífera no município de Candiota (RS)? Quais as representações sociais que os distintos atores sociais, particularmente aqueles situados no espaço rural, compartilham em torno dessa atividade?
Na tentativa de responder a essas questões, optou-se pelo arcabouço teórico-metodológico das Representações Sociais, de Serge Moscovici (1978), por meio da análise dimensional das representações, e da abordagem estrutural das Representações Sociais, de Jean-Claude Abric (1994). Para o desenvolvimento do trabalho, aplicou-se um roteiro de entrevistas semiestruturadas, entre janeiro e março de 2012, a 46 pessoas situadas direta ou indiretamente no espaço rural e envolvidas com a temática do carvão mineral.

Além desta introdução, o texto está estruturado em cinco seções. Na segunda seção, descreve-se o arcabouço teórico-metodológico das representações sociais logo após na terceira seção a metodologia. Na quarta, apresenta-se um breve contexto sobre a atividade carbonífera e o rural no município e suas representações. Na quinta, são expostas brevemente as abordagens dimensionais e estruturais das representações sociais da atividade carbonífera em Candiota. Por fim, na sexta seção são feitas algumas considerações finais.

\section{As representações sociais como arcabouço teórico-metodológico}

As representações sociais "podem ser compreendidas como fenômeno (objeto de estudo), como teoria (no sentido de explicação científica do fenômeno) e como 'metateoria' (a discussão em torno da teoria)" (VIANA, 2008, p. 45). É uma abordagem teórica acerca do saber popular e do senso comum que coletivamente são elaborados e reproduzidos a fim de construir e interpretar a realidade.

A teoria das representações sociais é tratada neste estudo como um arcabouço teórico-metodológico. O caráter teórico das representações sociais auxilia na construção do objeto de pesquisa e na explicação científica dos fenômenos, por meio de análises interpretativistas. O sentido metodológico se expressa na construção dos meios e instrumentos para análise de acordo com os pressupostos da teoria e obedecendo à iden- 
130 - Relações entre a Atividade Carbonífera e o Rural em Candiota, RS, Brasil: análises sobre representações sociais em um contexto de dilemas sobre a energia

tificação dos processos de construção das representações, as dimensões envolvidas e como se organizam.

As representações sociais são significados que os atores carregam consigo sobre um determinado objeto. Esses significados são construídos a partir da comunicação entre o grupo social, a influência das ideologias dominantes sobre o grupo e seus indivíduos e as percepções dos atores construídas sobre seus interesses. Para Moscovici,

"La representación social es una modalidad particular del conocimiento, cuya función es la elaboración de los comportamientos y la comunicación entre los individuos [...] La representación es un corpus organizado de conocimientos y una de las actividades psíquicas gracias a las cuales los hombres hacen inteligible la realidad física y social, se integran en un grupo o en una relación cotidiana de intercambios, liberan los poderes de su imaginación" (MOSCOVICI, 1979, p. 17-18).

De acordo com Moscovici (1979), a representação social é uma forma de conhecimento que permite a elaboração de comportamentos que expressam a atitude em relação a determinadas opiniões e concepções. Nesse sentido, o autor constrói a perspectiva das dimensões da representação social: informação, campo de representação e atitude. Optou-se por esta abordagem dimensional de conteúdo porque, segundo o autor (MOSCOVICI, 1978, p. 71), as dimensões "fornecem uma panorâmica do conteúdo e do sentido" das representações sociais. As dimensões permitiram tanto a construção do roteiro de entrevistas como a orientação para a análise.

De acordo com Mora (2002), o campo de representação expressa a hierarquia dos conteúdos de uma representação, e esta hierarquização se relaciona à ideologia dominante acerca de um determinado fenômeno social. A informação estará relacionada às informações que os atores possuem a respeito da exploração do carvão e aos veículos de informação. Quanto à atitude, está relacionada "en la vida corriente o desfavorable en relación con el objeto de la representación social" (MORA, 2002, p. 10). No empírico estudado, esta dimensão diz respeito à orientação geral de um determinado grupo de atores situados prioritariamente (não exclusivamente) no espaço rural. Nesta dimensão, entra em questão o posicionamento, a atitude em relação à percepção quanto às mudanças da paisagem, quanto à alteração nas dinâmicas sociais.

Para Jean-Claude Abric (1987 apud MENIN, 2007), a organização das dimensões da informação e atitude, de Moscovici, conferiria significações de acordo com a posição estrutural em relação a outros elementos. Abric (1994) sugere que as representações sociais são estruturadas por meio de um núcleo central de representações e elementos periféricos das representações sociais. O núcleo central determina a organização e o significado das representações, determinando também a variedade dos pontos que unem os seus elementos. Elementos centrais compõem o núcleo central representacional e esses elementos conferem os sentidos da representação social.

O núcleo central é composto de um ou alguns elementos que ocupam a estrutura de representação de uma posição privilegiada, dando sentido à representação. Esta última é determinada, em parte, pela natureza do objeto representado, por outro lado pela relação que o sujeito - ou grupo - tem com este objeto e, finalmente, por sistemas de valores e normas sociais que constituem o ambiente ideológico da época e do grupo (ABRIC, 1994). As representações sociais periféricas são instáveis e dinâmicas, mais suscetíveis às mudanças de contexto do que o núcleo central. As representações sociais periféricas e os elementos centrais fazem parte do universo consensual, sendo os primeiros reflexos de uma familiarização decorrente de mecanismos cognitivos.

\section{Metodologia}

A pesquisa foi realizada com 46 atores sociais no município de Candiota (Figura 1), com base prioritariamente no meio rural. Este município localiza-se na chamada "metade sul" do Rio Grande do Sul (mais propriamente na região da 
Figura 1. Mapa do Rio Grande do Sul destacando o município de Candiota (RS)

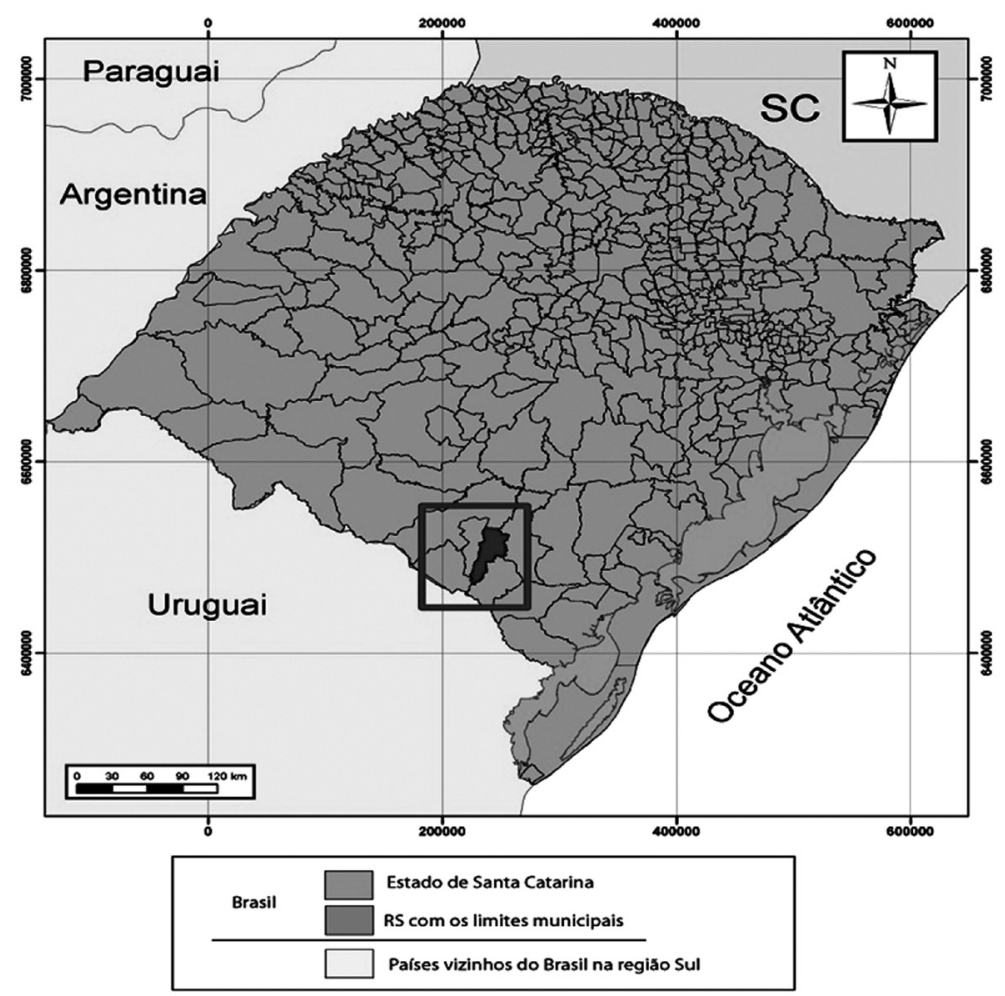

Fonte: Zvirtes (2013).

Campanha), a cerca de $400 \mathrm{~km}$ da capital, Porto Alegre. Foram realizadas entrevistas semiestruturadas, observações e anotações em diário de campo, além de registro fotográfico. A apreensão dos dados também compreendeu a análise de material impresso, cartazes e material de divulgação na imprensa (jornais, revistas, outdoors) e áudio de programas de rádio e TV. Houve a imersão total em campo, com moradia no município a fim de compartilhar experiências com os interlocutores no seu dia a dia, em reunióes e eventos. A condução da pesquisa compreendeu inicialmente uma fase de campo exploratória, finalizada em outubro de 2011, e a pesquisa de campo de janeiro a março de 2012.

Os distintos grupos sociais podem ter tanto uma representação central comum como os elementos periféricos das representações, sendo esses por vezes comuns ou distintos em relação aos outros grupos. De acordo com Pereira e Almeida,
"As representações sociais são representações de um objeto sustentadas por um determinado sujeito ou grupo. Nesse sentido, é de suma importância em um estudo sobre representações sociais a identificação dos grupos que interagem com o objeto, (re)construindo e (re)inventando as representações sociais" (PEREIRA e ALMEIDA, 2014, p. 136-137).

A escolha dos grupos sociais analisados se deu ao longo do trabalho de campo exploratório, a partir de entrevistas, informações e convivência no local de estudo em outubro de 2011. Os grupos, em um primeiro momento, foram mapeados e, a partir de então, foram buscados os informantes-chaves, estes os mediadores entre os pesquisadores e os grupos. Foram estabelecidos critérios para seleção dos grupos a serem analisados: relação de proximidade com o rural do município, conhecimentos sobre dinâmicas rurais em Candiota; envolvimento com a temática da atividade carbonífera e a importância 
132 - Relações entre a Atividade Carbonífera e o Rural em Candiota, RS, Brasil: análises sobre representações sociais em um contexto de dilemas sobre a energia

do grupo ou dos atores na formação de opinião sobre assuntos relacionados à atividade carbonífera e sua relação com o rural e/ou ambiente. Os entrevistados foram organizados em sete grupos sociais conforme sua própria identificação e seguidamente conforme o grupo social a partir de onde se dão suas relações cotidianas: agricultores (assentados), pecuaristas (não assentados), funcionários da prefeitura, técnicos de assistência técnica e extensão rural, trabalhadores das empresas carboníferas, ambientalistas, ex-agricultores e pecuaristas.

Os dados coletados foram armazenados no programa NVIVO7 e analisados a partir de categorização específica, o que no NVIVO é caracterizado como "nodes" ou "nós". Para Moscovici (1978), na codificação é preciso separar os aspectos centrados no grupo e os centrados no conteúdo. A codificação centrada no grupo reúne modalidades de expressão do grupo de acordo com o objeto. Na codificação centrada no conteúdo é possível a separação dos temas mais frequentes em relação ao problema e "também nos autoriza a definir o vocabulário que o expressa" (MOSCOVICI, 1978, p. 21). A partir das respostas dos entrevistados, os temas mais frequentes foram categorizados, assim como as respostas que diziam respeito às dimensões do universo de opinião: atitude, campo representacional e informação de forma separada. Foram analisados os consensos e dissensos entre os integrantes de um mesmo grupo e também as relações entre os grupos. Segundo Moscovici (1978), as categorias auxiliam na combinação dos discursos individuais e a operacionalizar as perguntas e respostas. A categorização auxilia nas análises e interpretação dos resultados.

Após a codificação, ainda com o auxílio do NVIVO7, foram selecionadas as palavras mais frequentes por meio da ferramenta queries, na ordem em que foram apresentadas pelo programa, conforme a citação no texto. Foram descritas as palavras mais frequentes e analisados os contextos em que apareciam no texto, a que outras palavras elas estavam relacionadas. A fim de verificar as representações sociais centrais e os elementos periféricos da representação, conforme Abric (1994), foram pesquisados os conteúdos das falas em que cada palavra apareceu. Existem programas de informática que auxiliam estas análises em um viés quantitativo, porém, optou-se por realizá-las manualmente ${ }^{4}$.

\section{A atividade carbonífera e o rural}

De acordo com Borba (2001, p. 1), o carvão mineral "é um combustível fóssil sólido formado a partir da matéria orgânica de vegetais depositados em bacias sedimentares" ${ }^{\prime \prime}$. Ele é responsável por cerca de $45 \%$ de toda a eletricidade gerada no mundo (IEA, 1997) e é o mais abundante dos combustíveis fósseis. Suas maiores reservas estão concentradas na América do Norte, Ásia e Europa, totalizando $81,5 \%$ das reservas mundiais. Na América do Norte, destacam-se os EUA, com cerca de $25 \%$ das reservas mundiais. Nas demais regiões, destacam-se a Rússia (16\%), China (12\%) e Austrália (9\%) (ATLAS DE ENERGIA ELÉTRICA DO BRASIL, 2002).

Apesar dos impactos no ambiente e na saúde das populações que convivem com essa atividade, segundo o Atlas de Energia Elétrica do Brasil (2002, p. 119), o carvão é considerado a maior fonte de energia para uso local e as principais razões são a abundância e distribuição geográfica das reservas e os baixos custos e a estabilidade nos preços relativamente a outros combustíveis. No Brasil, as concentrações significativas de carvão mineral estão nos estados do Rio Grande do Sul, Santa Catarina e Paraná; porém, as principais reservas estão localizadas no Rio Grande do Sul, que detém mais de 90\% das reservas nacionais (ATLAS DE ENERGIA ELÉTRICA DO BRASIL, 2002). Ainda de acordo com esta fonte, o carvão brasileiro significa apenas $0,2 \%$ na participação da produção mundial de

4. Sobre softwares de análises de conteúdo de representações sociais, é possível ver em Fleury (2008) e Leal (2010).

5. “O carvão mineral não é um mineral no sentido estrito da palavra e não possui uma composição química definida. Trata-se de um recurso energético e, entre estes, luta com o petróleo e o gás natural pela supremacia" (SOARES, 2008, p. 13). 
carvão mineral (WCI, 1999 apud BORBA, 2001), e suas jazidas, em torno de 1,2\% das reservas mundiais, ao final de 1999 correspondiam a 32 bilhões de toneladas. Quanto ao uso energético, no Brasil o carvão é bastante restrito, representando apenas 6,6\% da matriz energética nacional, de acordo com o Balanço Energético Nacional do Ministério de Minas e Energia (2003).

O debate sobre a matriz energética é um tema bastante atual: a meta anunciada pelo governo federal brasileiro seria de eliminar a pobreza a partir do desenvolvimento econômico, cujo elemento essencial é a energia, tanto para consumo do setor primário (extrativismo, agricultura) e secundário (indústria), quanto para o setor de prestação de serviços e para uso de outros consumidores. Logo, no Brasil, o tema da geração de energia está estreitamente relacionado ao debate sobre "desenvolvimento econômico" e, segundo o Plano Nacional de Energia 2030 (2007), em quaisquer cenários apresentados o consumo do carvão para geração de energia tende a aumentar progressivamente até 2030. Apesar do veto da entrada do carvão no leilão de energia em 2012, ao final de março de 2013, o ministro de Minas e Energia, Edson Lobão, assegurou a inclusão do carvão mineral no leilão de energia do segundo semestre. Em 2013, especificamente em Candiota, eram quatro os grandes empreendimentos que podiam se candidatar ao próximo leilão: UTE Sul e UTE Seival, ambas pertencentes à MPX, empresa de energia de Eike Batista; UTE Pampa, do grupo Tractebel, e UTE Jaguarão, da Star Energy, do grupo Bertin (COLUSSI, 2013).

Além da importância para a matriz energética nacional, a exploração do carvão em Candiota é representada por alguns atores como importante para a economia da região devido à geração de empregos atuais (FRITZ, 2004) e na geração de futuros empregos. Seria um empreendimento que se mostra necessário também ao desenvolvimento econômico regional.

As representações sociais da atividade carbonífera estão relacionadas àquelas do meio rural do município, que também integra um importante setor para a economia regional. Segundo dados do Departamento de Processamento de Dados do estado do Rio Grande do Sul, em 2012, Candiota tinha 1.481 estabelecimentos rurais. Destes, 831 pertencem a famílias assentadas, representando $56 \%$ do total de estabelecimentos do município e $27 \%$ da área total. Os assentamentos representavam $61 \%$ do total de unidades da agricultura familiar. A média de terras de cada lote nos assentamentos era de 28 hectares. A agricultura de base familiar, com área menor ou igual a 112 ha, representava $92 \%$ dos estabelecimentos rurais de Candiota. As médias propriedades, com quantidade de terra maior que 112 ha e menor que 500 ha, correspondiam a 91 estabelecimentos, ou seja, 6,2\% do total; a grande propriedade, maior ou igual a $500 \mathrm{ha}$, correspondia a 27 estabelecimentos (1,8\%) que, juntas, somavam 17.226,83 hectares, ou $172.268 \mathrm{~km}^{2}$, representando $18,45 \%$ da área do município (SITAGRO, 2012). Esses dados demonstram que a região é majoritariamente composta por estabelecimentos agrícolas familiares.

A exploração do carvão na perspectiva do crescimento econômico também está muito atrelada às interpretações que os atores possuem do meio rural. Ao representarem esse espaço como sinônimo de atraso e o carvão como sinônimo de desenvolvimento econômico e fator de atração de investimentos, a produção agropecuária e a própria vida no campo tornam-se algo insustentável. As dificuldades para se viver e produzir no campo estão na zona de limite entre as facilidades de oportunidades de se manter na cidade. É como se os agricultores e pecuaristas vivessem no campo sendo atormentados pela dificuldade e pelo atrativo da vida na cidade, algo que seria consequência de uma produção rural inviável, pouco ou nada lucrativa. Contraditoriamente, ao mesmo tempo em que, para os agricultores pecuaristas entrevistados, viver no campo também é sinônimo de qualidade de vida, viver nesse espaço com dificuldades e na pobreza não é desejável. Sendo assim, é preferível que os filhos migrem para a cidade, que se tornem técnicos e trabalhem para as empresas carboníferas. A migração para a zona urbana e o apoio à explora- 
134 - Relações entre a Atividade Carbonífera e o Rural em Candiota, RS, Brasil: análises sobre representações sociais em um contexto de dilemas sobre a energia

ção do carvão não são apenas estimulados pelas facilidades e maiores oportunidades da cidade, mas também pela motivação principal para a mudança de vida, evitando-se as dificuldades de se permanecer no campo.

Para os agricultores assentados, ambientalistas, o grupo de trabalhadores de empresas carboníferas e quadros da prefeitura de Candiota entrevistados, a qualidade de vida estaria muito mais relacionada às oportunidades de renda geradas pelo desenvolvimento a partir da exploração da atividade carbonífera na região. Enquanto para os agricultores pecuaristas a qualidade de vida é diretamente relacionada a um viver bem no campo, para os agricultores assentados, ela estaria relacionada à ida para cidade em busca de empregos formais.

Entre os agricultores e pecuaristas entrevistados, a opinião majoritária é de apoio à atividade carbonífera, seja pelas relações familiares com pessoas que dependem diretamente da atividade, ou pela perspectiva de se ter uma alternativa econômica perante as dificuldades na produção rural. Ao mesmo tempo em que o ambiente é tratado como o "ingrediente da agricultura", entendido como algo intocado, "a ser preservado para as futuras gerações", admitem-se os problemas ambientais ocasionados pela mina a céu aberto e a geração de energia na termelétrica Presidente Médici. Porém, na mesma medida em que se admitem os problemas ambientais, estes também são negados. Em muitos casos, quando se perguntou ao entrevistado se sabia ou ouviu falar de algum problema ambiental que tivesse como causa as atividades carboníferas, as respostas foram negativas. Logo em seguida, com a mesma pergunta colocada de outra forma, a resposta é de que inevitavelmente a atividade carbonífera ocasiona problemas ambientais.

\section{As abordagens dimensionais e estruturais das representações sociais da atividade carbonífera em Candiota}

O campo representacional sobre a atividade carbonífera concentra-se no entorno da representação central de crescimento econômico (Figura 2). De forma simplificada, as representações periféricas que se destacam são as que atribuem às atividades da usina e da mina o sinônimo de emprego, qualidade de vida, razão de existência do município, energia, atração de investimentos e atraso do campo.

Figura 2. Representações sociais da atividade carbonífera em Candiota (RS)

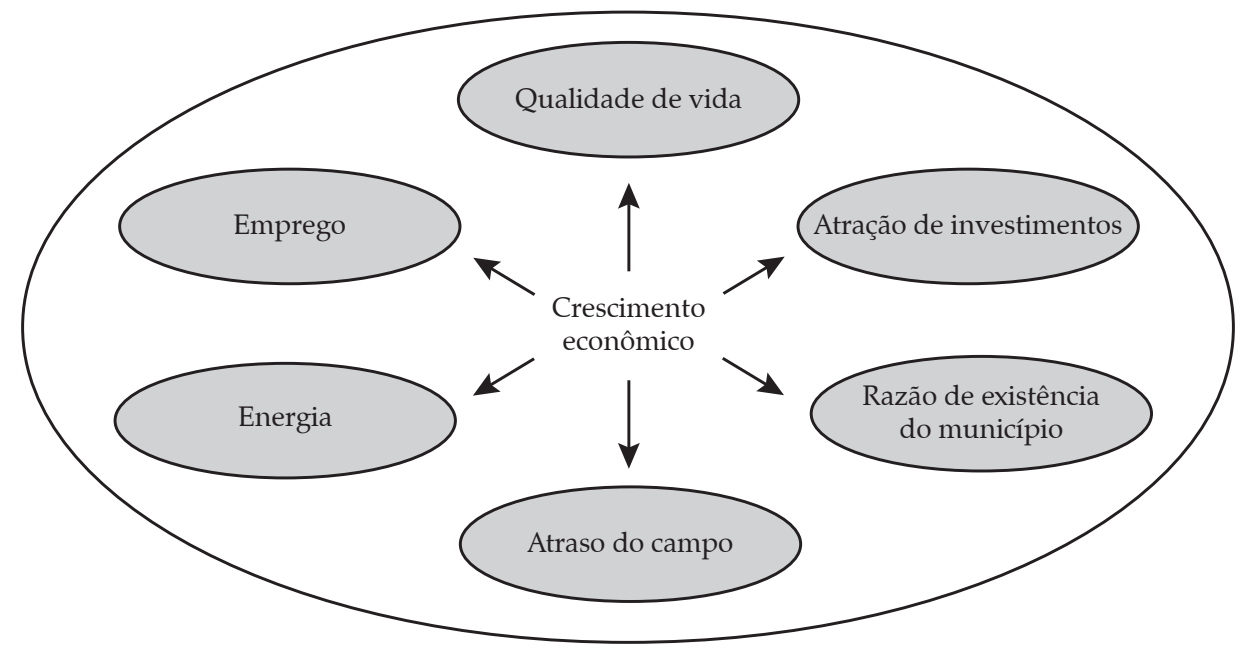

Fonte: Pereira (2013). 
O crescimento econômico é entendido como meio e como fim para a geração de empregos, por exemplo. Esta representação é expressa pelo poder público e pelas empresas como um meio, ou seja, a partir do crescimento econômico gerado pelo carvão, mais empresas e mais empregos seriam criados, com mais renda. Assim, a população teria melhor qualidade de vida, proporcionando condições para a "existência" do município.

As empresas carboníferas, por um lado, contribuem sobremaneira para a arrecadação de tributos e, por outro, justificam a necessidade do poder executivo local em fomentar as medidas institucionais que possam viabilizar as atividades das empresas. Para os funcionários da prefeitura, a justificativa para a continuação da exploração do carvão é a necessidade e viabilização do crescimento econômico que estaria sendo proporcionado por essa atividade. Para os entrevistados não ligados à prefeitura e às empresas, a exploração do carvão "é o que se tem no momento", mas se entende que outras fontes de emprego e de tributos podem ser adotadas, bem como outras formas de geração de energia sustentáveis ambiental e economicamente.

As representações sociais são formadas por intermédio da informação, do posicionamento e do campo representacional entre os atores. As representações sociais sobre as vantagens do crescimento econômico levam a um olhar favorável à exploração do carvão. Reconhece-se uma vantagem da economia atrelada ao carvão.

A mídia, representada pelo jornal local, corrobora as representações favoráveis ao carvão (Figura 3). Os meios de comunicação de massa transmitem informações do poder público e das empresas, ancoradas em pressupostos técnico-científicos (universo reificado). Conclui-se que a comunicação midiática é a fonte de informação da população em geral, transmitindo o posicionamento favorável, justificado por meio de argumentos científicos ligados à área da engenharia. Em Candiota, o universo reificado cria condições para reprodução do universo consensual entre os grupos. São as informações provenientes de estudos técnicos em relação às possibilidades de diminuição ou amenização dos efeitos poluidores tanto da mineração quanto da usina termelétrica que auxiliam no processo da formação de uma opinião favorável. A população do município, normalmente, em seu cotidiano, confia nesse universo reificado que traz a possibilidade de segurança, sendo mais uma forma de tornar real e objetiva a atividade carbonífera.

Figura 3. Fontes de informação sobre o carvão mineral em Candiota (RS) (2011-2012)

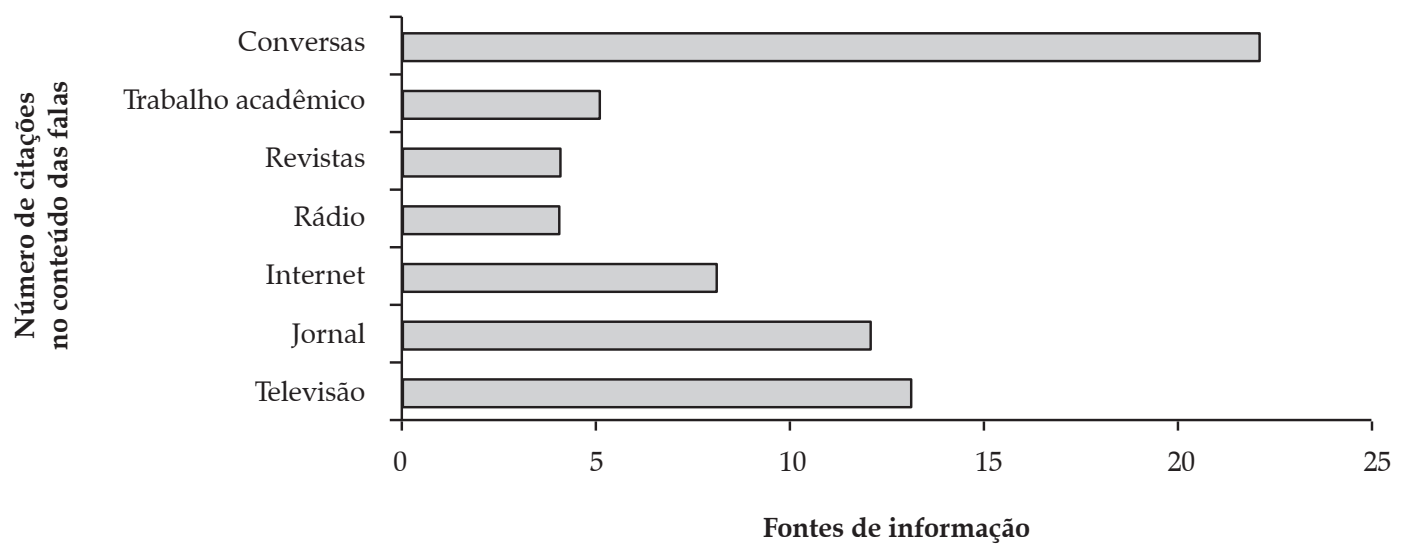

Fonte: Adaptado de Pereira (2013, p. 69). 
136 - Relações entre a Atividade Carbonífera e o Rural em Candiota, RS, Brasil: análises sobre representações sociais em um contexto de dilemas sobre a energia

As manifestações contrárias, de forma geral, situam-se no plano da comunicação cotidiana: não há setores contrários organizados dentro do município, mas há a organização de grupos favoráveis. Os principais fatores que permeiam o imaginário dos atores que não se consideram favoráveis e nem contrários estão relacionados à dimensão cultural e econômica. O caráter cultural é proveniente da posição do ator social como filho, neto e atualmente mineiro; também pelo fato de ter sido o primeiro e único emprego de muitos entrevistados. Este último exemplo confunde-se com a dimensão econômica, pela dependência em relação ao emprego, seja próprio ou de familiares e amigos. Segundo dados do Ministério do Trabalho (MTE, 2013), em Candiota, havia 1.053 trabalhadores formais na atividade carbonífera, incluindo os trabalhadores da mina de carvão, da indústria de transformação e serviços industriais, em um universo de 8.771 habitantes, segundo o Censo do IBGE de 2010. De acordo com relatos de moradores do município e do prefeito, toda renda da cidade estava relacionada aos empregos diretos e indiretos, principalmente no setor de serviços, gerados pela atividade no município. A Companhia Rio-Grandense de Mineração (CRM), em 2012, mantinha o maior número de empregados na mineração, sendo 168 trabalhadores da empresa e 68 terceirizados, somando 356 trabalhadores (REVISTA MINEIROS, 2012).
A respeito da orientação geral dos indivíduos em relação ao objeto de representação, 53\% são favoráveis à exploração do carvão, $28 \%$ são contrários e $19 \%$ não se consideram nem favoráveis, nem contrários.

O grupo favorável é composto por funcionários das empresas carboníferas, um ambientalista de Candiota, dois técnicos da assistência técnica e extensão rural, um ex-agricultor e pecuarista que hoje trabalha na cidade, três agricultores, seis pecuaristas e dois membros do grupo da prefeitura. A justificativa favorável é de que a exploração e a geração de energia por meio do carvão mineral são importantes economicamente para a região de Candiota. Sendo assim, ela atrairia empregos, é uma alternativa aos produtores rurais em tempos de estiagem e garante o abastecimento de energia elétrica no estado. Ademais, já existiriam hoje meios tecnológicos para amenizar os danos ambientais provocados pela atividade.

O grupo contrário é composto de um ambientalista que mora em Porto Alegre, sete técnicos da assistência técnica e extensão rural, um trabalhador de empresa carbonífera, um ex-agricultor que mora na cidade e quatro assentados, estes últimos residentes no município de Candiota. O principal argumento deste posicionamento diz respeito aos danos ambientais que a geração de energia fundada no carvão provoca, como se pode demonstrar nos fragmentos da fala de dois entrevistados:

Tabela 1. Posicionamento sobre a atividade carbonífera, conforme a distribuição das interpretações nos grupos em Candiota (RS), 2012

\begin{tabular}{lcccc}
\hline \multicolumn{1}{c}{ Grupo } & Favorável & Contrários & Nem favorável, nem contrário & Total \\
\hline Agricultores assentados & 5 & 4 & 2 & 11 \\
Pecuaristas & 5 & 0 & 1 & 6 \\
Ex-agricultores e pecuaristas & 1 & 1 & 1 & 3 \\
COPTEC & 1 & 3 & 0 & 4 \\
Emater & 1 & 0 & 1 & 2 \\
Bionatur & 0 & 2 & 0 & 2 \\
CGTEE & 4 & 0 & 1 & 5 \\
CRM & 6 & 1 & 0 & 7 \\
Ambientalistas & 2 & 1 & 1 & 4 \\
Prefeitura & 2 & 0 & 0 & 2 \\
Total & 27 & 12 & 7 & 46 \\
\hline
\end{tabular}

Fonte: Pereira (2013, p. 82). 
"Não apoio. A queima do carvão libera um monte de gases tóxicos, cinzas, são geradores de aquecimento global. Tem o resíduo né, a mina é a céu aberto, tá (sic) expondo o solo. A recuperação ambiental eles chamam de recuperação, mas só o nome todo mundo sabe que não recupera. O impacto visual é ruim, ver aqueles canos largando fumaça... pra mim seria mil vezes melhor ver o pampa sem ver aquela usina, aquele monstro cuspindo cinza. As plantações de eucalipto e aquela usina causam impacto ambiental" (Extensionista rural, Candiota).

“Não apoio, eles já é (sic) uma fonte obsoleta de energia... se houvesse uma nova tecnologia que o tratasse de uma forma mais limpa...mas hoje como tá. (sic)... a poluição dele não compensa... existe (sic) outras formas de produzir energia" (Trabalhador de empresa cabonífera).
Os entrevistados que deram o relato dos fragmentos anteriores, demonstraram, durante a entrevista, o entendimento da necessidade de buscar formas alternativas de energia, devido às consequências ambientais da atividade tanto da mina de carvão quanto da usina termelétrica. De forma geral, mesmo os entrevistados que se posicionaram favoráveis têm o entendimento quanto aos danos ambientais; porém, na visão do grupo contrário, o meio ambiente tem outras representações, o que reforça seus argumentos de ordem ambiental que dificilmente são contestados pelos outros grupos.

Por meio do modelo esquemático a seguir são indicadas as representações sociais, de maneira geral, dos atores favoráveis à atividade carbonífera (Figura 4):

Figura 4. Representações sociais generalistas de pessoas favoráveis à atividade carbonífera

Representações sociais gerais de pessoas favoráveis à atividade carbonífera

e que moram na cidade de Candiota e região, não possuem ligação com meio rural:

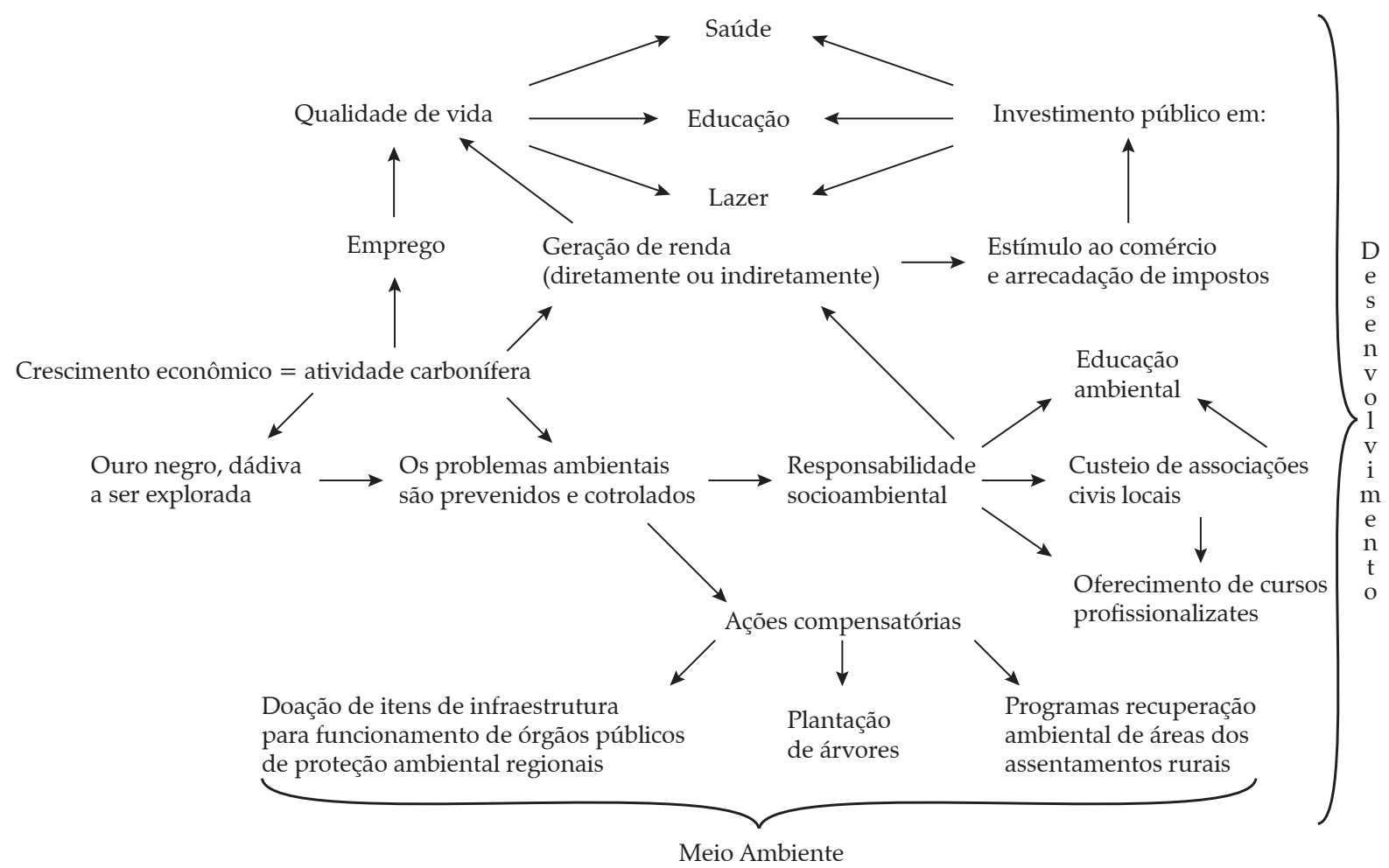

Fonte: Pereira (2013). 
138 - Relações entre a Atividade Carbonífera e o Rural em Candiota, RS, Brasil: análises sobre representações sociais em um contexto de dilemas sobre a energia

A pressão à inferência é um importante fator que influencia os atores na interpretação dos fatos e na construção de um posicionamento e sua atitude. Segundo Moscovici (1979), trata-se da pressão que os grupos exercem sobre seus membros para que se posicionem e corroborem um saber informal sobre um determinando assunto, pessoa ou objeto essencial para a constituição do grupo, permitindo manter uma coesão de suas ideias. Para Souza Filho (1993), a pressão à inferência "pode ser apreendida a partir da reconstituição de interações de sujeitos com membros do grupo de referência no qual se apoiam para produzir ou não representações sociais" (p. 120).

Nesse sentido, percebem-se as mudanças de atitude que denotam as relações de cumplicidade entre os entrevistados (sujeitos) e o grupo social ao qual pertencem e também a manutenção da centralidade da posição do grupo exercida sobre os indivíduos (Figura 5).

A cumplicidade aqui se refere aos indivíduos que favorecem a realização da atitude dos grupos, sendo a concretização da opinião em atos. Um exemplo seria quando os indivíduos apoiam e se integram às manifestações públicas favoráveis à continuidade do carvão. A centralidade revelava-se quando o entrevistado repete muitas vezes os mesmos argumentos expressos muitas vezes nas falas dos demais integrantes do grupo.

A opinião ou a prática contrária àquela construída pelo grupo pode gerar a exclusão dos contrários; sendo que essa exclusão não se demonstra apenas no pertencimento ou não àquele ou a este grupo, mas na vida da comunidade, em relação aos fatos sociais em que o indivíduo se envolve. Candiota tem sua rotina determinada pelas dinâ- micas geradas pela atividade carbonífera. Por ser um município de pequena população, os grupos sociais interagem e sabem quem são as pessoas que resistem ao senso comum. Da mesma forma, é possível mapear os atores e os pontos-chaves dos discursos que costumam conquistar adeptos para a manutenção da hegemonia de um grupo. A opinião com valoração negativa à exploração do carvão é considerada polêmica, como sendo a opinião de pessoas não bem quistas, enquanto a valoração positiva é entendida como sendo de alguém que quer progredir.

Em cada grupo social foi possível a identificação de um ator-chave que forma a opinião dos demais e desempenha o papel de manter a centralidade do grupo, ou seja, o posicionamento que é compartilhado pelos demais membros. Como, por exemplo, no grupo da assistência técnica e extensão rural, o coordenador de extensão rural, que geralmente conta com mais tempo de serviço, é quem exerce este papel. Na prefeitura, trata-se do prefeito. No grupo dos agricultores, se destacam os frades de uma congregação católica. Estes frades desenvolvem um trabalho político na região, a partir da influência que exercem principalmente sobre o grupo de agricultores assentados. Eles estão ligados a um movimento social que também atua na região com um determinado grupo de agricultores e lideram uma emissora de rádio local. Estes religiosos estão presentes na organização dos agricultores desde quando foram assentados na região há mais de 20 anos e hoje desenvolvem projetos socioambientais em parceria e patrocínio da Eletrobrás CGTEE (Companhia de Geração Térmica de Energia Elétrica), que administra as atividades

Figura 5. Relações de cumplicidade e centralidade entre grupos e indivíduos em Candiota (RS), 2012
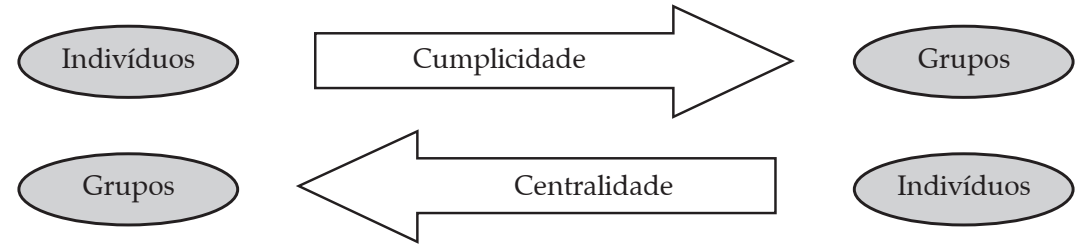

Fonte: Elaborado pelos autores. 
da usina termelétrica. Esses atores sociais, ao mesmo tempo em que atuam como atores-chaves na conservação da positividade da exploração do carvão, quando procurados optaram por não participar da pesquisa, bem como não quiseram expor o papel que desempenham neste contexto (PEREIRA, 2013).

Os pecuaristas residem longe uns dos outros, não possuindo uma convivência cotidiana, uma territorialidade compartilhada, o que de certa forma se observou como fator que dificulta a manutenção de uma unidade em torno de pautas coletivas. Por outro lado, os agricultores, por serem assentados, já têm outra lógica organizativa fomentada pelo movimento social ao qual pertenciam ou pertencem. Os pecuaristas entrevistados se pautaram pela opinião da assistência técnica e extensão rural, sendo a opinião dos técnicos respeitada e seguida por eles (PEREIRA, 2013). Porém, em relação ao tema do "emprego" em que os entrevistados se posicionam interpretando a relação entre a atividade carbonífera, o rural e os empregos, os técnicos da assistência técnica e extensão rural fazem várias referências enquanto apenas um pecuarista se referiu ao assunto.

A palavra emprego foi mencionada com maior frequência pelo grupo de representantes das empresas carboníferas, da assistência técnica e extensão rural e pelos agricultores. Os entrevistados das empresas ressaltaram a condição de serem empregados, que precisam do emprego e, para isso, da exploração do carvão. O emprego é apresentado como uma das consequências da exploração do carvão, como alternativa econômica às pessoas do meio rural que migram para a cidade. A observação e a vivência com a realidade local são essenciais para o entendimento da dinâmica da pressão de inferência.

Todos os grupos estão inseridos em um contexto maior, que influencia a construção das interpretações e a forma como essas interpretações podem ou não interagir com as ideias hegemônicas. Alguns posicionamentos apreendidos parecem apenas reproduzir construções de outros atores. Infere-se o poder de coerção tanto dentro dos grupos, o que faz com que todos sejam ou se demonstrem convencidos da opinião do grupo, ou em relação a grupos externos e aos atores formadores de opinião, como no caso do prefeito e frades que atuam sobre determinados grupos.

O governo federal, a partir do Ministério de Minas e Energia, elabora e executa as políticas energéticas setorialmente, que fazem parte de outra política macro, de desenvolvimento nacional, o Programa de Aceleração do Crescimento (PAC). Essa construção, por via institucional, chega ao município, que deve zelar pelo andamento da política nacional. Em Candiota, há setores político-econômicos com diferentes graus de dependência em relação à exploração do carvão, mas todos se unem pela motivação econômica. Essa união mantém a centralidade das opiniões e dos comportamentos aceitos pelo grupo, as atitudes dos atores são diretamente influenciadas por essa dependência e pela pressão de inferência dos grupos em torno do núcleo central das representações sociais.

Como visto, a atitude que prepondera entre os entrevistados em Candiota é dotada de positividade, ressaltando os benefícios da exploração do carvão. A própria migração das pessoas do meio rural para o urbano é vista por alguns atores como algo desejável, como uma ascensão social. No meio rural, os jovens, com mais frequência que os idosos, tendem a ver a migração como algo positivo. Para estes, a saída do campo é incentivada pelas empresas carboníferas, que oferecem qualificação e, em alguns casos, emprego em alguma atividade nas empresas terceirizadas. Em contrapartida, há representações dotadas de contrariedade, de negação. É como se a balança "pesasse" de acordo com a posição social: nem todos são totalmente a favor, nem todos são totalmente contra. Nesse sentido, destaca-se que o grau de dependência em relação à exploração do carvão é instável e dinâmico. Além disso, destaca-se a dimensão cultural, de identidade, que compõe o imaginário dos atores, pois um terço dos entrevistados, indiferente do grupo a que pertencem, pensam a atividade carbonífera a partir da tradição familiar: avô mineiro, pai mineiro e 
140 - Relações entre a Atividade Carbonífera e o Rural em Candiota, RS, Brasil: análises sobre representações sociais em um contexto de dilemas sobre a energia

hoje mineiro. A Companhia Rio-Grandense de Mineração (CRM) vem trabalhando na região desde 1961 e a vida útil da mina de carvão é de 330 anos (REVISTA MINEIROS, 2012).

\section{Considerações finais}

As representações sociais se processam em torno do entendimento que os atores têm sobre o mundo à sua volta, com base em suas experiências individuais e dos grupos sociais a que pertencem. No empírico estudado, as representações se constroem por meio das interpretações e percepções que os entrevistados possuem do meio rural, das ideias de desenvolvimento como processo ou um estágio. O contraste de um rural "atrasado" seria um meio urbano "moderno", repleto de contradições, desde as promessas de emprego que a atividade carbonífera proporcionaria às promessas de novas indústrias e empresas que não chegaram. A representação social central da atividade carbonífera como crescimento econômico remete à uma idealização de ascensão econômica do município, tanto na cidade quanto no campo, mas que, segundo os entrevistados, não é possível de ser visualizada de forma homogênea.

Os indicadores de desenvolvimento como o IDH, por exemplo, que em Candiota é considerado elevado $(0,818)$ (PNUD, 2000), contrastam com as percepções de qualidade de vida dos entrevistados (dignidade, comida, trabalho, viver com alegria, saúde, educação), pois, segundo eles, não estariam sendo proporcionados a todos os candiotenses. Os dados oficiais não revelam a má distribuição de renda do município, que é recorrentemente manifestada pelos atores. Ao mesmo tempo, o apelo propagandístico midiático das empresas, em especial da CGTEE/Eletrobrás, revela as parcialidades de uma realidade idealizada que é embutida no senso comum dos grupos sociais.

As ideias de desenvolvimento que os atores possuem se confundem com as representações da exploração do carvão, sendo por vezes um tratado como sinônimo do outro. Nesse sentido, sendo a atividade carbonífera vista como relacionada ao crescimento econômico, na medida em que este último deixa de ser consequência daquela, as interpretações também se modificam. O núcleo central das representações sociais se mantém estável enquanto os elementos periféricos apontam para a transformação do entendimento do fenômeno social.

Se as representações sociais, como indica Moscovici, são maneiras de tornar visível o que nos é invisível, em familiar o que não nos é familiar, no empírico estudado verifica-se um processo de desconstrução das representações sociais atuais. Constantemente produzem-se esses processos de ancoragem e objetivação, mas no empírico estudado o que já é familiar configura-se no início de um processo de desconstrução, tornando-se novamente não familiar. É a transformação das representações sociais no tempo e no espaço.

De acordo com Moscovici (2011),

“[...] os universos consensuais são locais onde todos querem sentir-se em casa, a salvo de qualquer risco, atrito ou conflito. Tudo o que é dito ou feito ali, apenas confirma as crenças e as interpretações adquiridas, corrobora, mais do que contradiz, a tradição. Espera-se que sempre aconteçam, sempre de novo, as mesmas situações, gestos, ideias" (p. 54).

A partir de mudanças conjunturais, o universo consensual dos entrevistados tende a ser também modificado por meio das relações sociais expressas no seu cotidiano. Neste caso, as formas como os sujeitos e grupos entendem a atividade carbonífera são influenciadas pela propaganda (informação), denotando a sua positividade e processando opiniões favoráveis. Já os elementos negativos, que auxiliam no processo de construção de representações contrárias à atividade, pertencem às relações cotidianas, sentidas e vividas no dia a dia dos cidadãos comuns.

O que antes estava em vias de concretização no universo consensual dos atores, passa novamente a tornar-se não familiar devido às incertezas ocasionadas pela mudança de conjuntura. Corroborando o pensamento de Moscovici, o homem comum 
“[...] pode experimentar esse sentido de não familiaridade quando as fronteiras e/ou convenções desaparecem; quando as distinções entre o abstrato e o concreto se tornam confusas; ou quando um objeto, que ele sempre pensou ser abstrato, repentinamente emerge com toda sua concretude etc." (MOSCOVICI, 2011, p. 54).

A ampliação da atividade carbonífera, bem como a flexibilização das leis ambientais integram e desencadeiam um universo consensual em transformação. O que antes parecia ter se concretizado, o que era estável e confiável, agora emerge em um contexto de dúvidas e incertezas. A atividade carbonífera passa a ser novamente incluída em uma categoria desconhecida, assim como era quando os agricultores assentados iniciaram o processo de ocupação dos campos na década de 1980. Isso ocorre também com os sujeitos que passam a conviver no município, que iniciam a descoberta de relações sociais cotidianas embebidas de dinâmicas sociais condicionadas ao contexto político do carvão mineral e os seus usos.

Em Candiota, a atividade carbonífera atualmente se encontra em processo de reapresentação para a população. Para Moscovici (2011), o “ato da reapresentação é um meio de transferir o que nos perturba, o que ameaça nosso universo, do exterior para o interior, do longínquo para o próximo" (p. 56-57). Para esse autor, o não familiar atrai e ao mesmo tempo intriga as pessoas e suas comunidades; ele causa furor e as obriga a explicitar as suposições implícitas, que são essenciais ao consenso. É o não familiar, o intrigante imergindo em um universo de dúvidas.

\section{Referências bibliográficas}

ABRIC, J-C. Represéntations sociales: aspects theóriques. In: ABRIC, J. C. (Org.). Pratiques sociales et représentations. Paris: PUF. 1994. 252 p.

Coopération, compétition et représentations sociales. In: MENIN, M. S. S. O aspecto normativo das representações sociais: comparando concepções. Revista de Educação Pública, Cuiabá/MT, v. 16, n. 30, p. 121-135, 2007.
ATLAS DE ENERGIA ELÉTRICA DO BRASIL 2002. Agência Nacional de Energia Elétrica. Brasília: ANEEL. 153 p.

BORBA, R. F. Balanço mineral brasileiro, carvão mineral. Brasília: Departamento Nacional de Produção Mineral (DNPM). 2001. 19 p.

BRASIL. Instituto Brasileiro de Geografia e Estatística (IBGE). Censo 2010. Disponível em: <http://www. censo2010.ibge.gov.br/> . Acesso em: 3 out. 2012.

BRASIL. Ministério de Minas e Energia. Balanço Energético Nacional (BEM). Brasília: MME, 2003.

. Plano Nacional de Energia (PNE) 2030: estratégias para a expansão da oferta. Brasília: MME/EPE, 2007. 324 p.

Ministério do Trabalho e Emprego (MTE) Informações para o Sistema Público de Emprego e Renda. Disponível em: < http://bi.mte.gov.br/bgcaged/caged_ isper/index.php>. Acesso em: 11 dez. 2014.

COLUSSI, J. Autorização de uso de carvão para energia destrava projetos de R\$ 10 bilhões. Jornal ZERO HORA on line 19 março 2013. Disponível em:<http://zerohora. clicrbs.com.br/rs/economia/noticia/2013/03/autorizacaode-uso-de-carvao-para-energia-destrava-projetos-de-r10-bilhoes-4079513.html> . Acesso em: 20 mar. 2013.

EIA- US Energy Information Administration. Today in Energy. Monthly coal and natural gas fired generation equal for first time in April 2012. Disponível em: < http://www. eia.gov/todayinenergy/detail.cfm?id $=6990>$. Acesso em: 28 set. 2014 .

FLEURY, L. C. Cerrado para ser o quê? Representações sociais e conflitos ambientais em torno do Parque Nacional das Emas, Goiás. Porto Alegre, 2008. 210 f. Dissertação (Mestrado em Desenvolvimento Rural) - Programa de Pós-Graduação em Desenvolvimento Rural, Universidade Federal do Rio Grande do Sul.

FRITZ, K. B. B. Impactos sócio-econômicos do uso do carvão mineral na região de Candiota, RS. In: TEIXEIRA, E. C. et al. (Org.). Estudos Ambientais em Candiota: carvão e seus impactos. Porto Alegre: FINEP/ PDACT/CIAMB/FAPERGS/ FEPAM, 2004.

IEA - International Energy Agency. Energy Technologies for the 21st Century, 1997. Disponível em: < http://www. iea.org/>. Acesso em: 9 out. 2011.

INTERNATIONAL ENERGY AGENCY (IEA). 1997. Energy Technologies for the 21st Century. Disponível em: < http://www.iea.org>. Acesso em: 9 out. 2011.

LEAL, S. M. C. Lugares de (não) ver? As representações sociais da violência contra mulher na atenção básica de saúde. 2010. 310 f. Tese (Doutorado em Enfermagem) - Programa de Pós-Graduação em Enfermagem, 
142 - Relações entre a Atividade Carbonífera e o Rural em Candiota, RS, Brasil: análises sobre representações sociais em um contexto de dilemas sobre a energia

Universidade Federal do Rio Grande do Sul, Porto Alegre. 2010. p. 39-68.

MORA, M. La teoría de las representaciones sociales de Serge Moscovici. Athenea Digital, Barcelona, n. 2 outoño, 2002. Disponível em: <http://psicologiasocial. uab.es/athenea/index.php/atheneaDigital/article/ view/55/55 > . Acesso em: 5 nov. 2012.

MOSCOVICI, S. A representação social da psicanálise. Rio de Janeiro: Zahar, 1978, 291 p.

El Psicoanálisis, su imagen y su público. Buenos Aires: Huemul, 1979, 363 p.

- Representações sociais: investigações em psicologia social. 8. ed. Petrópolis: Vozes, 2011, 404 p.

PNUD - Programa das Nações Unidas para o Desenvolvimento (PNUD) (2000). Ranking decrescente do IDH-M dos municípios do Brasil. Atlas do Desenvolvimento Humano. Acesso em: 11 out. 2011.

PEREIRA, V. C. O rural e o carvão: representações sociais em Candiota-RS. 2013. 165 f. Dissertação (Mestrado em Desenvolvimento Rural) - Programa de Pós-Graduação em Desenvolvimento Rural, Universidade Federal do Rio Grande do Sul, Porto Alegre. 2013.

PEREIRA, V. C. e ALMEIDA, J. P. A atividade carbonífera e suas representações no sul do Brasil, Cuadernos de Desarrollo Rural, Bogotá, v. 11, n. 73, p. 129-148, 2014.
REVISTA MINEIROS. Candiota/Carvão mineral, 2012. Disponível em: <http://www.revistaminerios.com.br/ Publicacoes/4797/CANDIOTA_CARVO_MINERAL. aspx>. Acesso em: 22 dez. 2014.

RIO + 20. O Futuro que nós queremos. Declaração final da Conferência das Nações Unidas sobre Desenvolvimento Sustentável. Conferência das Nações Unidas sobre Desenvolvimento Sustentável. Rio de Janeiro, Brasil, 20 a 22 de Junho de 2012. Disponível em: < http://www. mma.gov.br/port/conama/processos/61AA3835/OFuturo-que-queremos1.pdf > . Acesso em: 28 set. 2014.

SITAGRO. Secretaria da Fazenda do Estado do Rio Grande do Sul. Relatório de estabelecimentos rurais por município. Porto Alegre: PROCERGS. 2012. 180 p.

VIANA, N. Senso comum, representações sociais e representações cotidianas. Bauru: São Paulo: Edusc, 2008

ZVIRTES, G. Mapa do estado do Rio Grande do Sul e limítrofes com destaque ao município de Candiota. 2013. Elaborado a pedido dos autores.

WORLD COAL INSTITUTE (WCI). Participação da Produção Mundial de Carvão Mineral (1999). In: BORBA, R. F. Balanço Mineral Brasileiro, Carvão Mineral. Brasília: Departamento Nacional de Produção Mineral (DNPM). 2001. 19 p. 